the Ozark region of northwestern Arkansas and southwestern Missouri. Two separate archaeological cultures are distinguished. Harrington called the earliest remains the Ozark Bluff-Dwellers culture, and the group of traits that was occasionally found on top of some of the sites he called the "Top-Layer" culture. Upon the conclusion of the excavations in the Ozark region Mr. Harrington visited an Iowa Indian settlement in northeastern Kansas where he came into contact with a non-professional archaeologist, Mr. Edward Park. Upon examination of Mr. Park's collection Harrington noticed that the remains of a culture said to be the latest in that region, "was characterized by a series of objects identical with those the writer (Harrington) had found to be typical of the 'top-layer culture' in the Ozark rockshelters."

The possibility that the latest culture, as identified by Park, might be Kansa remains, and the "Top-Layer" Osage, is set forth in the Anthropologist article. W. D. Strong in his Introduction to Nebraska Archaeology, on page 284 refers to Harrington's paper and mentions that the Nebraska culture is also found in northeast Kansas. There is a possibility, says Strong, that the "latest culture" of Park may be a development out of the Nebraska culture, and also that it might be Oneota. The list of traits given by Harrington for the "TopLayer" is as follows: small, of ten triangular flint arrowpoints; double-pointed, sharply beveled knives; duck-bill or spoon-shape scrapers; the celt; flat, circular hammer-grinders; mortars with a cup-shape cavity; small L-shape catlinite pipes; grooved sandstone shaft smoothers; bone fishhooks; corn; shelltempered pottery of globular form, flaring rim, angular incised decoration, and flat, strap-like handles. This complex of traits certainly identifies the "TopLayer" as a division of the Mississippi Pattern. Unfortunately, Harrington was unable to illustrate these finds in this short report.

The latest work by Hill and Wedel, Vol. XVII, No. 1, Nebraska History Magazine, identifies the "latest culture" of Park with the Oneota of Iowa. Therefore, on the basis of the list of traits given by Harrington and his statement regarding its resemblance to the "latest culture" in northeastern Kansas, I should like to point out the probability that Harrington's "Top-Layer" will eventually be classified in the Oneota aspect of the Upper Mississippi phase.

JAMES B. GRIFFin

Ceramic Repository

University of Michigan

Ann Arbor, Michigan

\title{
Reversed Stratigraphy
}

In a recent publication, George C. Vaillant states: "Archaeological dating, in the absence of specific written testimony, depends on stratigraphy, the study of sequence in the ground of layers of human culture. Especially favorable for such research are rubbish heaps, since the objects at the base of an 
undisturbed midden must be older than those at the top, which were obviously the most recently deposited." ${ }^{208}$

Dr. Vaillant's faith in the chronological sequences embodied in undisturbed refuse mounds may never be betrayed, for ancient Mexicans may never have had the annoying tendency of some ancient Southwesterners to move the material of old dumps, redeposit it on top of their contemporaneous refuse, cover it with the growing accretion of daily refuse, and then perhaps move more old refuse on top. Such a dump, when tested by the archaeologist, certainly has not been disturbed since it was laid down in the present sequences, but "the objects at the base" of this "undisturbed midden" are not all "older than those at the top," although they were obviously the most recently deposited. Kidder encountered this situation at Pecos, and between 1928 and 1934 I found myself faced with the problem of determining the inversion of strata in the large east dump of Chetro Ketl, Chaco Canyon, New Mexico, and then of working out the pottery sequence from its inverted stratigraphy. ${ }^{209}$

In this case, strata 1 and 3 , counting up from the bottom, and strata 2 and 4 looked alike, but 1 and 3 differed slightly from 2 and 4 in showing lenses of ash and charcoal, while the other two showed the material more mixed and lumpy. This suggested that the lense-marked strata were of daily dump, while the other was re-dumped material cleared from some old kiva or room later built up and put into use again. The suggestion looked far fetched, however, for this would place half the mound as re-dumped material. Other evidence was necessary.

Fortunately we were accustomed to tree ring work in this area, and although small chunks of charcoal occurring in a dump had never before been tried out for dates, we had saved them from our strata tests. They were preponderantly piñon, with an appreciable percentage of pine. A piñon master chart was drawn up from the usable fragments, averaging about an inch from exterior to interior rings. This chart was fitted onto the known pine master chart for the area, and the fragments were thus dated. In a number of cases the charred bark still adhered to the wood. The dates checked the supposition of inversion and at the same time closely dated the associated pottery, for the potsherds and the charcoal from the house fires had been thrown out together. With the exception of the small amount of daily refuse being thrown out while the huge amounts of old trash were being moved, the material at the bottom of this section of the dump and in the third stratum, about two feet above and two to three feet thick, was later in origin than anything else in this mound, which measured twenty feet in height.

Hence, unhappily, we can scarcely say that it is obvious that "the objects

${ }^{208}$ Vaillant, George C., The History of the Valley of Mexico, Natural History, p. 325 , Nov., 1936.

200 Hawley, 1934. 
at the base of an undisturbed midden must be older than those at the top." In every ointment there is some fly.

FLORENCE M. HAWLEY

University of New Mexico

Albuquerque, New Mexico

\section{Credit to Professor Moorehead}

Through an oversight no reference was made, in a paper on the "The Simple Bone Point" of the Shell-Heaps of the Northeastern Algonkian Area(This series Vol. I, No. 4, 1936), to the contributions of Professor Warren K. Moorehead on the subject. In view of the extent of his archaeological explorations in Maine this was most unfortunate and the author hastens to apologize. It may be pointed out, however, that in the above paper, as the title indicates, no attempt is made to deal with the general subject of the archaeology of Maine, but the subject matter is for the most part restricted to the consideration of a single type of object.

The description of bone points of the type under discussion furnished in Professor Moorehead's report: Archaeology of Maine, Andover Press, 1922, is, to say the least, meagre. Under the title "Long Bones," there are about eight sentences having direct reference to these points in which the only descriptive terms employed are "small, pointed, polished objects." The brief discussion deals otherwise almost wholly with hypothesis. An excellent photographic plate bearing the legend: "Fig. 100. Typical arrow-points and fish hooks of which several thousand have been found,-From shell heaps. S. 1-1." serves nevertheless definitely to identify them. The selection of specimens of sharppointed, complete bone points for this illustration has failed not only to bring out a very characteristic feature, namely, the almost constantly occurring fracture and chipping, of a type that could be accomplished only by violent terminal impact, but also other characteristics such as the extent of the surface polished, bipolar and bilateral asymmetry, are not adequately shown, and orientation is neglected.

Professor Moorehead's recently expressed views in regard to the significance of the bone points in question (This series, Vol. II, No. 2, 1936) appear to lack factual support. The important and regularly occurring characteristic of dulling through successive terminal impacts is again omitted from his discussion. While we see no reason why sharpened bone points should not have been employed on the coast of Maine for fishhooks and gorges, this possibility furnishes no basis for the assumption that bone objects of a special type regularly showing fracture by terminal impact were so used. The polishing and continued use in many instances of dull and fractured points of this type, without sharpening, seems incompatible with the fishhook hypothesis. The possible usage of the simple bone point for purposes for which it was not intended 